\title{
El mercado no nace, se hace:la semilla de marañón y las mujeres de COAGRUM
}

\author{
Fátima Corea ${ }^{1}$ \\ 1. Investigadora social independiente. \\ e-mail: fatimanic@hotmail.com
}

Recibido: abril 2005 / Aceptado: junio 2005

ESTE ARTÍCULO SE BASA EN UN ESTUDIO QUE ANALIZÓ EL MODELO DE comercialización de la semilla del marañón. Esta actividad se fundamenta en la autogestión, es ideada y apoyada por el CIPRES y, es realizada por las mujeres de la Cooperativa Agroindustrial Unión de Mujeres Campesinas de Tecuaname, la Paz Centro. Entre los hallazgos principales, se identificó todo el recorrido de la producción de esta empresa, basada en un modelo organizativo que hallevado a las mujeres a asumir lentamente diferentes roles, mediante la construcciòn de relaciones sociales con lazos fuertes entre su organización y un aliado clave que facilita la solidez de la cooperativa en medio de las fluctuaciones del mercado, y ayuda a comercializar la semilla de marañòn desde Tecuaname hasta España.

Palabras clave: mujeres-comercio, semillas, marañón

\section{Introducción}

En Nicaragua, la producción agropecuaria enfrenta un proceso de debilitamiento progresivo porque la economía campesina dedicada a la finca, obtiene menos dinero cada vez. El sector agropecuario es el más marginado y excluido del país y, cada día, se evidencia que el sector privado convencional se retira de las áreas productivas agropecuarias y forestales. El neoliberalismo agudiza la situación mediante la apuesta a la importación y a la liberación - comercial, porque la lógica de la economía capitalista afirma que quien tiene capital, acumula; mientras que la lógica del pequeño productor no persigue la acumulación como primer objetivo, sino la satisfacción de las necesidades básicas integrales.

Ante la necesidad de desarrollo y capitalización de los pequeños productores, las organizaciones no gubernamentales como el Centro para la Promoción, la Investigación y el Desarrollo Rural y Social (CIPRES) se han involucrado en la búsqueda de soluciones, definiendo estrategias y acompañando a las unidades económicas campesinas a recorrer el camino desde la producción hasta la exportación. Con este propósito, realizó una labor de acompañamiento con las mujeres de la cooperativa COAGRUM, en Tecuaname. 
Según el MAG-FOR, el marañón se perfila como un producto que puede ayudar a solucionar los problemas de pobreza y poca productividad en las zonas secas del país, porque es un cultivo que se adapta a condiciones de suelo de ladera y bastante degradados; además, es resistente a la sequía y sirve para la reforestación.

Por otro lado, es un cultivo que no se produce en los países desarrollados y se considera internacionalmente como "lujoso y exótico", y ha logrado imponerse en el mercado y en los gustos de los consumidores europeos y norteamericanos.

"El comercio de la nuez de marañón se ha expandido vertiginosamente, siendo los Estados Unidos el mayor importador, (más de 60 mil toneladas métricas al año), seguido de Holanda, Alemania y Gran Bretaña, entre otros" (Martínez, 2001). Por lo tanto, la comercialización del marañón es una buena oportunidad para los productores y para las mujeres de COAGRUM.

Sin embargo, a pesar del tiempo de acompañamiento e inyección económica, y del buen perfil que tiene el producto para fines comerciales, esta experiencia tiene resultados ambiguos. La cooperativa cuenta con un saber acumulado pero, a la vez, las mujeres no logran conquistar el mercado e incidir en él. Por lo tanto, las preguntas que guiaron la investigación fueron: ¿Cómo ha evolucionado el modelo con las mujeres de la cooperativa de COAGRUM? ¿Por qué los resultados aún no son muy satisfactorios en cuanto a conseguir que el mercado trabaje para ellas?

Para las ciencias sociales, es importante realizar estudios como éste, donde se estudia la comercialización desde una perspectiva amplia, no estrictamente económica. Hay diversos estudios que se enfocan hacia la rentabilidad económica, excluyendo el análisis de las relaciones sociales y de las interacciones que se desarrollan a lo interno de los procesos de comercialización, pese a que estos vínculos entre los diferentes actores es determinante en el mercado.

La intención general del estudio fue analizar el modelo de comercialización basado en la autogestión, a partir de la experiencia de las mujeres de la cooperativa de COAGRUM. Para ello, se estudiaron las diferentes fases de la cadena de comercialización de la semilla de marañón, la lógica de los actores sociales que participan en este proceso y las relaciones sociales que se construyen entre los actores.

\section{Materiales y métodos}

Éste es un estudio de caso enfocado en la experiencia de comercialización que realizan las mujeres de COAGRUM desde el ámbito interno y desde la dinámica en que se desarrolla la cooperativa, sus estrategias de organización, las relaciones que se han construido entre las socias y las que se dan con el resto de los actores que intervienen en el proceso.

Los resultados de esta investigación nos permiten caracterizar el desempeño de la cooperativa de las mujeres de COAGRUM y la función de los demás actores que intervienen en la cadena de comercializacion: la cooperativa de COAGRUM se ubica en la comunidad de Tecuaname, en la Paz Centro, y está integrada por 20 mujeres. Otros actores son el CIPRES y los 
intermediarios involucrados en la cadena de comercialización del marañón.

\subsection{Técnicas para la recolección de datos}

La recolección de datos se realizó con el método de trabajo de campo interactivo, con entrevistas semi-estructuradas, para que las personas entrevistadas sintieran mayor libertad e iniciativa para responder.

Se realizó la observación participante; se convocó un grupo focal para evaluar la experiencia en su conjunto, a partir de la técnica FODA; se revisaron los archivos de la cooperativa, incluyendo recibos y controles de comercialización; y se hizo una revisión bibliográfica, como una de las técnicas de investigación documental, para complementar, ordenar y sistematizar los datos obtenidos, porque no se recomienda adentrarse en un estudio sin tener un referente teórico y un conocimiento a priori.

Se constituyeron seis diferentes grupos de investigadoras con diferentes temas que, a lo largo del proceso, conjuntamente y orientadas por el equipo de investigación de NITLAPAN, desarrollaron de manera sistemática sesiones de análisis, discusión, reflexión y talleres sobre aspectos teóricos y metodológicos relacionados con los hallazgos en los distintos estudios, lo que enriqueció significativamente la experiencia.

\subsection{Organización del trabajo}

Se llevó a cabo un proceso de aproximación inicial para establecer un primer contacto mediante una entrevista realizada al equipo del CIPRES, que sirvió de enlace con la cooperativa. La primera visita se aprovechó para generar confianza, para dar a conocer el objetivo de la investigación y realizar las primeras entrevistas. Para ello, se visitó a las mujeres en sus casas, en las comunidades.

En total, se realizaron 17 entrevistas a mujeres de la cooperativa que miembros de la junta directiva, de la junta de vigilancia y de la asamblea de socias. Se entrevistó a dos técnicos y tres funcionarios del CIPRES que les apoyan directamente, además de entrevistas, visitas y conversaciones realizadas a los intermediarios en los diferentes puestos de venta del producto.

Esto permitió identificar los actores y redes sociales que intervienen en el proceso, obtener la información necesaria para determinar la cadena de comercialización y para definir cómo se forma el precio del producto dentro de la cadena.

Tras este primer periodo, se ordenaron y transcribieron las entrevistas en memorias para visualizar omisiones. A continuación, se empezó una nueva ronda de entrevistas con las cooperadas y el personal del CIPRES para confirmar algunos datos, aclarar dudas y discutir resultados preliminares.

Por último, se procedió a analizar los resultados contrastando el marco teórico con los resultados de la investigación, lo que permitió llegar a las conclusiones y recomendaciones. 


\section{Hallazgos de la investigación}

\subsection{El modelo autogestionario de COAGRUM}

Se puede definir un modelo como "una representación simplificada de lo que acontece, esto quiere decir que el modelo no es isomórfico con la realidad, si bien permite comprender los procesos sociales implicados, aunque se pierda cierta información sobre la realidad" (Giner, 1998:498).

Los elementos ideológicos que fundamentan el modelo han surgido del CIPRES, que ha apuntado a desarrollar algunas experiencias de comercialización con campesinos en situaciones de extrema pobreza, como las mujeres de COAGRUM en Tecuaname, quienes han llevado a la práctica este modelo, donde son indispensables los elementos de asociatividad y autogestión.

Cuadro 1. Elementos del Modelo de Autogestión

\begin{tabular}{|c|c|c|c|}
\hline $\begin{array}{l}\text { Bases del } \\
\text { modelo }\end{array}$ & $\begin{array}{c}\text { Características del } \\
\text { modelo }\end{array}$ & Supuestos & Alcances \\
\hline $\begin{array}{l}\text { Un Grupo } \\
\text { formalmente } \\
\text { organizado } \\
\text { y registrado } \\
\text { jurídicamente. }\end{array}$ & 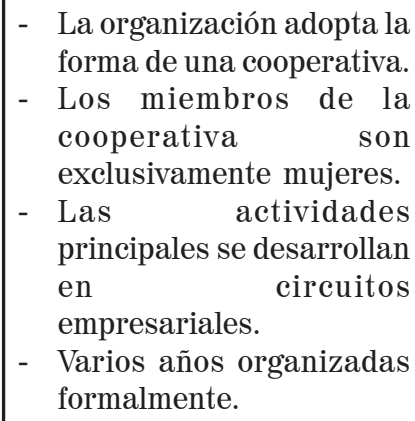 & \begin{tabular}{|l} 
- La cooperativa \\
a g r o i n d u s t r i a l \\
representa la posibilidad \\
de asociatividad de las \\
mujeres para desarrollar \\
un proceso de trabajo, \\
beneficios y realizar una \\
gestión colectiva. \\
- Es una organización en \\
busca del desarrollo de \\
su capital humano.
\end{tabular} & $\begin{array}{l}\text { - Limitado por el entorno de } \\
\text { libre comercio debido a la } \\
\text { tendencia individualista. } \\
\text { - } \text { Relaciones y lazos muy } \\
\text { fuertes entre las mujeres } \\
\text { miembro de la cooperativa } \\
\text { que las hace ir más allá de } \\
\text { intereses económicos. } \\
\text { - La unidad de producción se } \\
\text { encuentra distante de su } \\
\text { principal mercado. }\end{array}$ \\
\hline \begin{tabular}{|c|} 
Enfoque \\
asociativo \\
$\mathrm{y}$ \\
autogestionario \\
entre \\
mujeres.
\end{tabular} & $\begin{array}{l}\text { - Desarrollar un espacio de } \\
\text { acción colectiva para las } \\
\text { mujeres como nuevas } \\
\text { sujetas económicas es } \\
\text { muy importante en su } \\
\text { propia comunidad. } \\
\text { - } \text { Estar organizadas les da } \\
\text { prestigio } \\
\text { reconocimiento a nivel } \\
\text { local. } \\
\text { - Requiere el desarrollo de } \\
\text { una visión de largo plazo } \\
\text { y de acompañamiento } \\
\text { externo. }\end{array}$ & $\begin{array}{l}\text { - Realizar una gestión } \\
\text { democrática o colectiva } \\
\text { de los recursos en } \\
\text { función de sus intereses } \\
\text { y necesidades y a la vez, } \\
\text { unificar esfuerzos para } \\
\text { beneficio común de } \\
\text { todas. } \\
\text { - Irrumpir las reglas del } \\
\text { ámbito doméstico de las } \\
\text { mujeres, conquistando } \\
\text { un espacio en el ámbito } \\
\text { público, como es el del } \\
\text { mercado, es posible } \\
\text { cuando se cuenta con } \\
\text { presión externa. Así se } \\
\text { contribuye al desarrollo } \\
\text { de capacidades } \\
\text { autogestionarias. }\end{array}$ & $\begin{array}{l}\text { - Abre posibilidades para } \\
\text { desarrollar capacidades y } \\
\text { habilidades desiguales entre } \\
\text { las mujeres en su micro } \\
\text { espacio. } \\
\text { - La lejanía en que se } \\
\text { encuentran respecto al } \\
\text { mercado y la falta de medios } \\
\text { de comunicación, las ha } \\
\text { condicionado a depender de } \\
\text { un aliado externo clave } \\
\text { llevándolas a cierto grado de } \\
\text { dependencia que puede ser } \\
\text { negativo para el desarrollo } \\
\text { de los nexos con el mercado }\end{array}$ \\
\hline
\end{tabular}




\begin{tabular}{|c|c|c|c|}
\hline $\begin{array}{l}\text { Un Aliado } \\
\text { c l a v e } \\
\text { externo. }\end{array}$ & 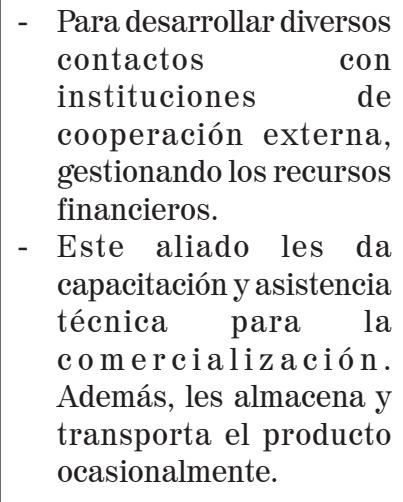 & $\begin{array}{l}\text { - Las mujeres, por su } \\
\text { propia cuenta, no pueden } \\
\text { ni saben cómo } \\
\text { comercializar desde } \\
\text { donde producen. } \\
\text { Necesitan de un aliado } \\
\text { externo. } \\
\text { - Las mujeres son el } \\
\text { germen de una nueva } \\
\text { economía, pero necesitan } \\
\text { ser formadas con el } \\
\text { apoyo de una instancia } \\
\text { fuera de la comunidad. }\end{array}$ & $\begin{array}{l}\text { - Limitado por falta de } \\
\text { recursos propios. } \\
\text { - Falta de experiencia } \\
\text { respecto de la } \\
\text { comercialización. }\end{array}$ \\
\hline $\begin{array}{l}\text { D i ve r s i - } \\
\text { ficación de } \\
\text { actividades. }\end{array}$ & $\begin{array}{l}\text { - No se enfocan } \\
\text { exclusivamente en la } \\
\text { comercialización. El } \\
\text { modelo apunta a que ellas } \\
\text { desarrollen más } \\
\text { capacidades que las que } \\
\text { el mercado requiere. } \\
\text { - En elaño 2002, solamente } \\
\text { procesaron el marañón } \\
\text { por cinco semanas, lo } \\
\text { que demuestra que } \\
\text { necesitan de otros } \\
\text { ingresos para subsistir. }\end{array}$ & $\begin{array}{l}\text { - A largo plazo, ellas van a } \\
\text { poder defenderse } \\
\text { generando riqueza que } \\
\text { les permita primero } \\
\text { subsistir y, luego de } \\
\text { diferentes productos } \\
\text { vender el excedente. }\end{array}$ & $\begin{array}{l}\text { - Limitado, dado que diluye los } \\
\text { esfuerzos para la } \\
\text { comercialización del } \\
\text { marañón, aunque ha } \\
\text { permitido que ellas hagan } \\
\text { frente al déficit que se ha } \\
\text { dado en su procesamiento. }\end{array}$ \\
\hline $\begin{array}{l}\text { Alto } \\
\text { Subsidio }\end{array}$ & $\begin{array}{l}\text { - Han recibido } \\
\text { financiamiento mediante } \\
\text { dinero en efectivo, en } \\
\text { especie y } \\
\text { acompañamiento. desde } \\
\text { que han estado aliadas } \\
\text { con el Ciprés. }\end{array}$ & $\begin{array}{l}\text { - Las mujeres no tienen } \\
\text { recursos para invertir, ni } \\
\text { capacidad de pagar. }\end{array}$ & $\begin{array}{l}\text { - Genera mayor dependencia, } \\
\text { limitando de la organización } \\
\text { respecto a su aliado. }\end{array}$ \\
\hline
\end{tabular}

Fuente: elaboración propia en base a entrevistas a las mujeres de Tecuaname y al CIPRÉS.

El modelo, que a corto plazo no se muestra como una experiencia consolidada, requiere un proceso de larga duración, ya que va mas allá de la comercialización: incluye la diversificación de actividades para el autoconsumo; además, implica la inversión de muchos recursos para que logre operar, pero ha sido una alternativa que ha proporcionado a las mujeres cooperadas los medios para crear una fuente de trabajo, tanto para ellas como para la comunidad.

\section{2 ¿Cómo se organiza la venta del Marañón, desde la producción?}

Para mostrar todo el recorrido del marañón, desde su estado bruto hasta el consumidor final en forma de producto elaborado, se utilizó el enfoque de análisis sub sectorial, donde las cadenas son definidas como "el conjunto de canales alternativos en un sistema de producción y distribución de un producto o un grupo de productos” (Parrilli, 2002:11). 
Las cadenas se producen alrededor de un producto específico, ligando actores, organizaciones, procesos y actividades dentro de la economía mundial. Estas cadenas son organizaciones ligadas con diferentes tipos de sub-contratos, tecnologías y funciones, coordinadas por diferentes actores, integrados específicamente y de forma vertical, y sobrepasan las fronteras nacionales hacia el nivel internacional, como sucede con la semilla del marañón que, desde la comunidad de Tecuaname, en la Paz Centro, llega hasta España.

Mediante el estudio, se identificó una cadena de comercialización como se presenta en el siguiente ilustración 1.

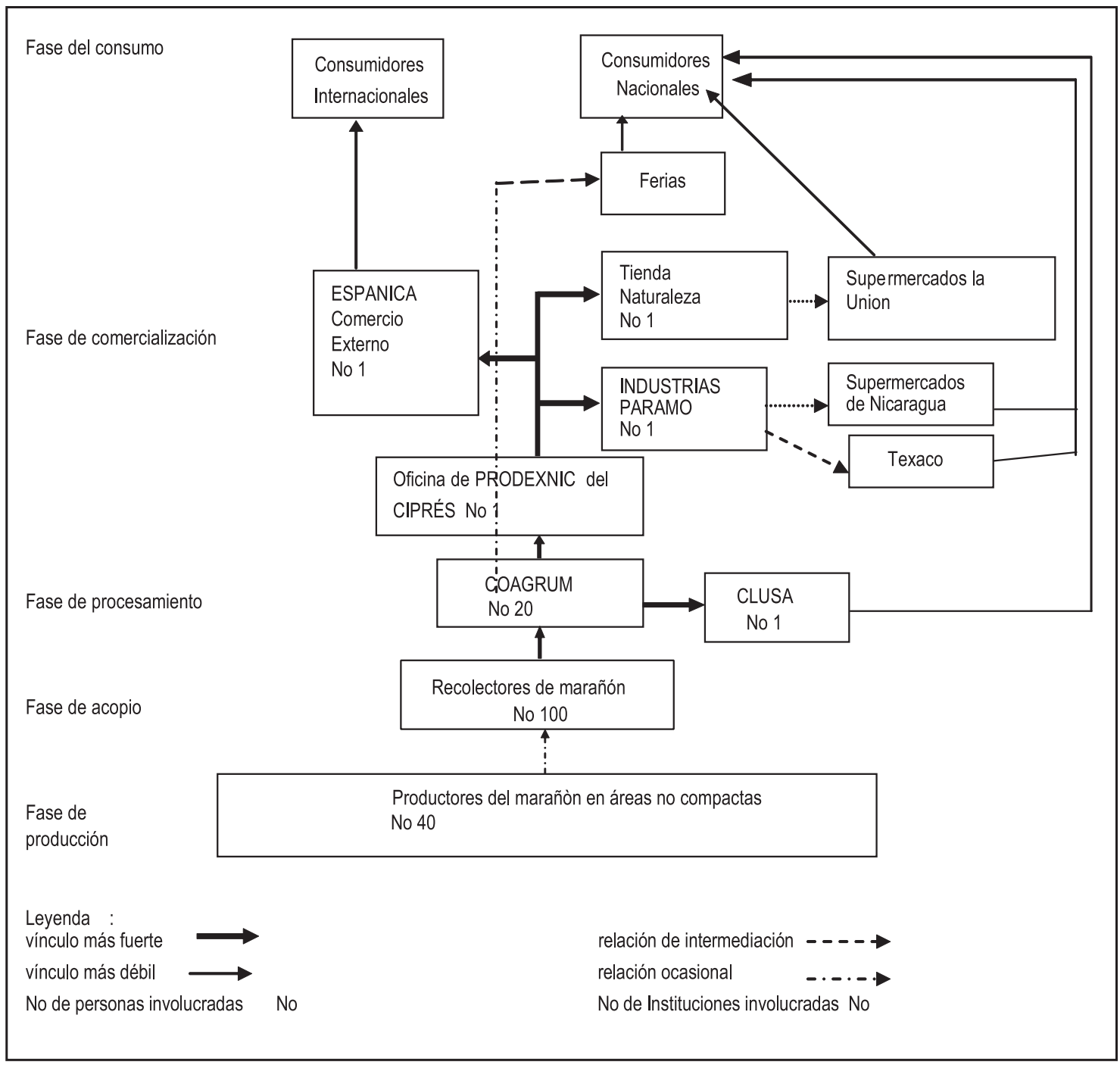

Ilustración 1. Cadena de comercialización del marañón (COAGRUM)

Fuente: elaboración propia sobre la base de entrevistas realizadas a las mujeres de COAGRUM, al CIPRES, a CLUSA y a Tienda Naturaleza. 
Esta cadena de comercialización de la semilla del marañón se presenta actualmente como una cadena semi-integrada, con tendencia a que en los próximos tres años se dé una integración total de sus distintas fases, ya que la cooperativa cuenta con 10 manzanas de tierra en vías de producción.

En su conjunto, están involucradas un total de 120 personas en la fase de producción y acopio del marañón, e intervienen cinco instituciones. Además, a lo interno de la cadena, en el año 2002 se movieron un promedio de 900 libras de semilla procesada de marañón. La cadena abarca desde el espacio local hasta un segmento de mercado internacional y se desarrolla en cuatro fases que se describen en el siguiente cuadro 2.

\section{Cuadro 2. Descripciòn de las fases de la cadena de comercialización del marañón}

\begin{tabular}{|c|c|}
\hline Fases & Descripción \\
\hline 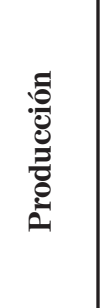 & $\begin{array}{l}\text { En la comunidad del Papalonal y de Tecuaname, en la Paz Centro, hace más de } 20 \text { años, existen } \\
\text { plantaciones de marañón dispersas en áreas no compactas. Los propietarios son } 30 \text { productores } \\
\text { del Papalonal y } 10 \text { de Tecuaname que no utilizan el marañón desde hace varios años. La cooperativa } \\
\text { cuenta con una plantación propia de } 10 \text { manzanas para la producción del marañón que, en seis } \\
\text { años de existencia, no ha dado los frutos esperados. La proliferación de plagas, el huracán } \\
\text { "Mitch" y la sequía han tenido efectos negativos para la producción. Además, el marañón se } \\
\text { siembra de manera aleatoria y esporádica por las familias, dentro de los sistemas de patio y no de } \\
\text { áreas compactas en parcelas, lo que representa una de las mayores limitaciones para su explotación. }\end{array}$ \\
\hline 耪 & $\begin{array}{l}\text { Hay cien recolectores de marañón entre productores de marañón y sus familias, viudas y madres } \\
\text { solteras con sus hijos, todos residentes de la comunidad de Tecuaname y sus alrededores quienes, } \\
\text { en los meses de Marzo, Abril y Mayo, recogen y venden la semilla para acopiarla a la cooperativa de } \\
\text { COAGRUM. Es una actividad bastante remunerada, porque la cooperativa paga } 150 \text { córdobas el } \\
\text { quintal de semilla recogido pero, actualmente, el acopio se encuentra en déficit, ya que en el año } \\
\text { solamente se lograron acopiar } 60 \text { quintales, aunque la planta tiene capacidad para procesar mil } \\
\text { quintales al año. Las mujeres necesitan desarrollar más sus capacidades gestionarias para buscar } \\
\text { el producto en bruto por ellas mismas, dentro y fuera del país. Al parecer, las mujeres creen que } \\
\text { el acopio es una responsabilidad compartida con el CIPRÉS, cuando el papel del CIPRÉS es tan } \\
\text { sólo de apoyo. La búsqueda del producto es, exclusivamente, responsabilidad de las cooperadas. }\end{array}$ \\
\hline 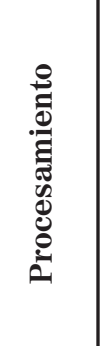 & $\begin{array}{l}\text { Participan } 20 \text { mujeres de la cooperativa, es exclusivamente artesanal, son ellas las que toman las } \\
\text { decisiones, establecen los horarios y organizan la rotación del trabajo, hasta asegurar el empaque } \\
\text { del producto. Las fechas en que van a procesar son definidas de acuerdo a la demanda y a la } \\
\text { existencia de semilla. En el } 2002 \text {, solo se procesó la semilla en tres ocasiones, en un periodo de } \\
\text { cinco semanas en todo el año. El pago de mano de obra se determina en función de la productividad } \\
\text { y, en una semana de procesamiento de } 20 \text { quintales de marañón, se utilizan un total de } 1,890 \\
\text { cordobas entre las } 20 \text { mujeres de la cooperativa. Ésta es una de las fases de la cadena que las } \\
\text { mujeres han asumido con mayor capacidad y excelencia, producciendo un producto de muy } \\
\text { buena calidad, que llegan a los supermercados de más prestigio de Managua. }\end{array}$ \\
\hline 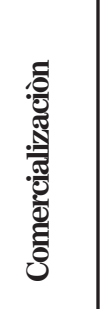 & $\begin{array}{l}\text { Para asumir la comercialización directamente, la cooperativa enfrenta ciertas desventajas. Una de } \\
\text { ellas es su ubicación, ya que se encuentra a } 81 \mathrm{~K} \text { m de la capital, no tienen teléfono para comunicarse } \\
\text { directamente con los clientes, el único medio de comunicación es a través de las emisoras nacionales } \\
\text { por donde el CIPRES les avisa si hay que traer producto para alguno de sus clientes en Managu y } \\
\text { sólo hay un bus diario que viaja hasta Managua. Pese a estas desventajas, han logrado organizar } \\
\text { el proceso de comercialización con el apoyo directo de la oficina de comercialización PRODEXNIC } \\
\text { del CIPRES. En esta fase se encuentran involucrados cinco actores principales: CIPRES, Industrias } \\
\text { Páramo, Tienda Naturaleza, ESPANICA y CLUSA. }\end{array}$ \\
\hline
\end{tabular}




\section{3 ¿ Quiénes compran el marañón y a qué precio?}

En la comercialización de la semilla de marañón, se encuentran involucrados, dos ONGs, dos intermediarios que venden solamente productos de origen orgánico y una empresa que se dedica a comercializar varios productos tipo "snack" ( ver cuadro 3).

Cuadro 3. Clientes de la semilla de marañón

\begin{tabular}{|c|c|c|c|c|}
\hline Clientes & Función & Antigüedad & $\begin{array}{l}\text { Cantidad que } \\
\text { compra en } \\
\text { bolsa de } 3 \text { onzas } \\
\text { a COAGRUM c/ } \\
\text { año } \\
\end{array}$ & Lugares de venta \\
\hline $\begin{array}{l}\text { Industrias } \\
\text { Páramo }\end{array}$ & $\begin{array}{l}\text { - Distribuidor casi exclusivo de } \\
\text { la semilla del marañón y de } \\
\text { otros productos tipo "snack". }\end{array}$ & 5 años & $\begin{array}{l}-1997-1998= \\
\text { màs de } 5000 \\
\text { bolsas. } \\
-1999-2002= \\
3000 \text { bolsas. }\end{array}$ & $\begin{array}{ll}\text { - } & \text { Supermercados } \\
& \text { La Colonia } \\
\text { - } & \text { E s t a c i o n e s } \\
& \text { Texaco } \\
\text { - } & \text { En mini super }\end{array}$ \\
\hline $\begin{array}{l}\text { Tienda } \\
\text { Naturaleza }\end{array}$ & $\begin{array}{l}\text { - Compra el producto a granel y } \\
\text { lo empaca con su sello o lo usan } \\
\text { combinado con otros } \\
\text { productos para distribuirlo a } \\
\text { supermercados La Unión. } \\
\text { Además, lo venden } \\
\text { directamente al consumidor. }\end{array}$ & 3 años & 6 quintales & $\begin{array}{l}\text { - } \mathrm{T} \text { i e } \mathrm{n} \mathrm{d} \text { a s } \\
\text { naturistas } \\
\text { - Supermercado la } \\
\text { Unión }\end{array}$ \\
\hline $\begin{array}{l}\text { Población } \\
\text { en general } \\
\text { q u e } \\
\text { visitan las } \\
\text { Ferias }\end{array}$ & $\begin{array}{l}\text { - Se realizan tres o cuatro ferias } \\
\text { al año, donde las mujeres } \\
\text { promocionan y venden el } \\
\text { marañòn, conectadas por el } \\
\text { CIPRES o invitadas } \\
\text { directamente por quienes } \\
\text { organizan las distintas ferias. }\end{array}$ & 4 años & 300 bolsas & $\begin{array}{l}\text { - Una feria- } \\
\text { CIPRES en su } \\
\text { local, una feria - } \\
\text { Red Agroforestal. } \\
\text { - Una feria - Clusa } \\
\text { - Hotel Intercon- } \\
\text { tinental. } \\
\text { - Una Feria - } \\
\text { Renicc }\end{array}$ \\
\hline ESPANICA & $\begin{array}{l}\text { - Organización compuesta por la } \\
\text { ONG española Asociación } \\
\text { Rubén Darío y la ONG } \\
\text { nicaragüense CIPRES, en } \\
\text { apoyo a la producción agrícola } \\
\text { campesina. }\end{array}$ & 2 años & 14 quintales & $\begin{array}{l}\text { - Tiendas, tanto en } \\
\text { Madrid, como en } \\
\text { las provincias de } \\
\text { España. }\end{array}$ \\
\hline CLUSA & $\begin{array}{l}\text { - Es una ONG llamada Liga de } \\
\text { Cooperativa de los EEUU. Inició } \\
\text { actividad en Nicaragua desde } \\
1995 \text {, compra a diferentes } \\
\text { cooperativas productos } \\
\text { orgánicos y los comercializa. } \\
\text { Además, desarrolla proyectos } \\
\text { de apoyo a productores } \\
\text { orgánicos. }\end{array}$ & 1 año & 3 quintales & $\begin{array}{l}\text { - Tienda Small } \\
\text { Farmer }\end{array}$ \\
\hline
\end{tabular}

Fuente: Elaboración propia, sobre la base de entrevistas realizadas al CIPRÉS e intermediarios. 
La comercialización es, dentro de la cadena, la función que más dificultades ha planteado a las socias de la cooperativa. Ellas esperan que el mercado llegue a ellas y han salido poco en su busca. Muestra de ello es que, desde el inicio, tenían bastante semilla procesada, pero no tenían comprador, hasta que el CIPRES conectó a la mujeres con el propietario de Industrias Páramo y, paulatinamente, con casi todos los demás clientes.

El precio del marañón ha sido determinado por las mujeres en relación a los costos de producción y de mano de obra empleada en el procesamiento, pero se da una variación en el precio con que llega al consumidor ya que, en el proceso, cada intermediario, de manera individual, va agregando valor al producto.

Cuadro 4. Formación del precio de la nuez del marañón

\begin{tabular}{|l|l|l|l|l|}
\hline Intermediarios & \multicolumn{1}{|c|}{$\begin{array}{c}\text { Precio del } \\
\text { Productor }\end{array}$} & \multicolumn{1}{|c|}{$\begin{array}{c}\text { Precio de la } \\
\text { cooperativa }\end{array}$} & $\begin{array}{c}\text { Precio del } \\
\text { intermediario }\end{array}$ & \multicolumn{1}{|c|}{$\begin{array}{c}\text { Precio al } \\
\text { Consumidor }\end{array}$} \\
\hline Industrias Páramo & $\mathrm{C} \$ 2$ & $\mathrm{C} \$ 7$ & $\mathrm{C} \$ 5$ & $\mathrm{C} \$ 17.50$ \\
\hline CLUSA & $\mathrm{C} \$ 2$ & $\mathrm{C} \$ 8$ & $\mathrm{C} \$ 7.50$ & $\mathrm{C} \$ 17.50$ \\
\hline ESPANICA & $\mathrm{C} \$ 2$ & $\mathrm{C} \$ 12.5$ & $\mathrm{C} \$ 6.35$ & $\mathrm{C} \$ 20.85$ \\
\hline
\end{tabular}

Fuente: elaboración propia, sobre la base de entrevistas realizadas a las mujeres de la cooeprativa, al CIPRÉS e intermediarios.

\subsection{Redes sociales que intervienen en la comercialización del marañón}

Entender la comercialización como el vínculo entre productores y consumidores, implica que existen diferentes prácticas sociales que influyen en las relaciones comerciales ya que, detrás del comercio y del producto, los actores sociales se relacionan y forman cierto tipo de "alianzas" y de "redes" sociales. Estas redes son vínculos entre actores que se basan en la confianza y reciprocidad y no se restringen a la pertenencia a una organización. La función de estas redes es asegurar la sobrevivencia y el apoyo mutuo.

Una red se define como "el conjunto bien delimitado de actores, individuos, grupos y organizaciones, comunidades y sociedades, vinculados unos con otros, a través de una relación o conjunto de relaciones sociales como entidades sociales" (Lozares, 1999:108).

Los vínculos existentes entre COAGRUM y los demás actores de la cadena se muestran en el siguiente diagrama. 


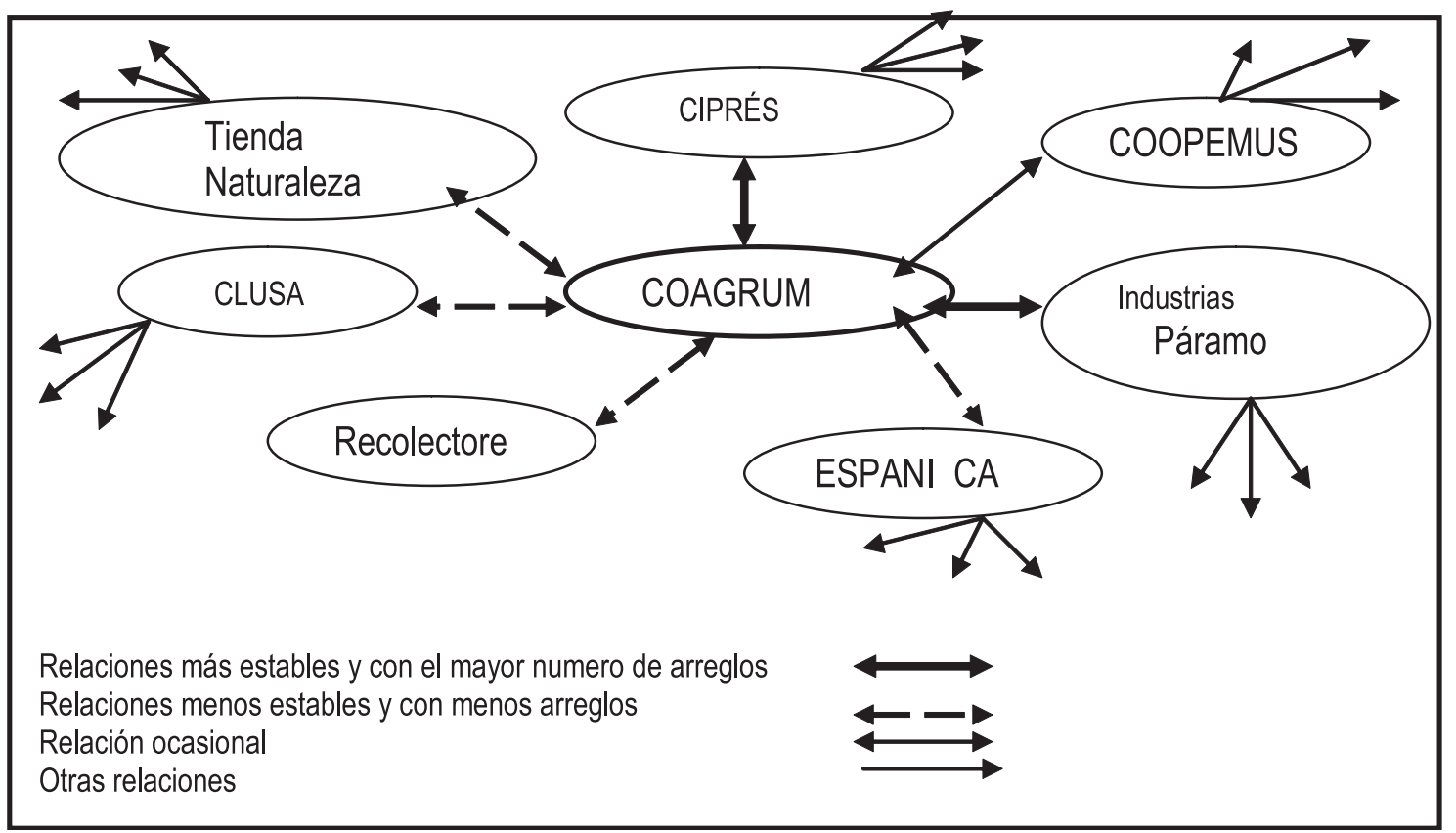

Ilustración 2. Relaciones encontradas entre COAGRUM y actores de la cadena

Diferentes tipos de relaciones se han ido construyendo en los seis años de vida de la cooperativa. Son relaciones que se visualizan claramente de acuerdo a lo que da COAGRUM y a lo que recibe de sus clientes (ver cuadro 5).

Cuadro 5. Caracterización de la relación entre COAGRUM y actores involucrados

\begin{tabular}{|c|c|c|}
\hline Actores & Qué reciben de COAGRUM & Qué da a COAGRUM \\
\hline CIPRES & 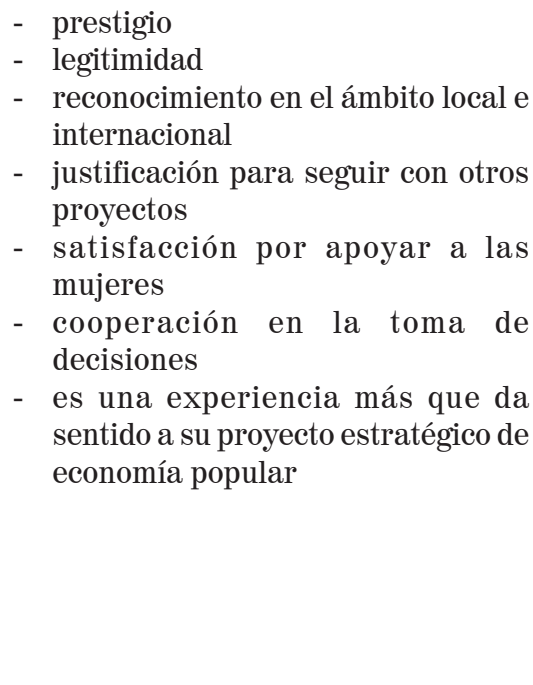 & $\begin{array}{l}\text { - tiene la idea y formula el } \\
\text { proyecto } \\
\text { - gestiona los recursos } \\
\text { financieros } \\
\text { - capacitación y asistencia } \\
\text { técnica para cada fase dentro } \\
\text { de la cadena } \\
\text { - durante seis años, ha asumido } \\
\text { la búsqueda de clientes } \\
\text { - guarda el producto y ayuda } \\
\text { ocasionalmente en el transporte } \\
\text { desde Tecuaname hasta } \\
\text { Managua (oficinas del CIPRES) } \\
\text { - tiene un rol protagónico } \\
\text { - acompañamiento y asesoría a } \\
\text { las mujeres en la } \\
\text { comercialización de la nuez } \\
\text { - ayuda para la exportación }\end{array}$ \\
\hline
\end{tabular}




\begin{tabular}{|c|c|c|}
\hline $\begin{array}{l}\text { Industrias } \\
\text { Páramo }\end{array}$ & $\begin{array}{l}\text { - crédito para la venta de la semilla } \\
\text { procesada de marañón en el } \\
\text { mercado } \\
\text { - prestigio como empresa en el } \\
\text { mercado al presentar producto de } \\
\text { buena calidad }\end{array}$ & $\begin{array}{l}\text { - distribución casi exclusiva del } \\
\text { producto por cinco años } \\
\text { - colocación del producto en los } \\
\text { supermercados de Managua y } \\
\text { en otros puntos de venta } \\
\text { - una relación conflictiva debido } \\
\text { a la falta de pago } \\
\text { - no cumplimiento de las } \\
\text { cláusulas del contrato } \\
\text { - su primer cliente }\end{array}$ \\
\hline $\begin{array}{l}\text { Tienda } \\
\text { Naturaleza }\end{array}$ & $\begin{array}{l}\text { - producto a granel, como semilla } \\
\text { entera y quebrada para } \\
\text { comercializar. } \\
\text { - precios más bajos del mercado } \\
\text { - la autorización para ponerle la } \\
\text { marca de Tienda Naturaleza y otro } \\
\text { empaque }\end{array}$ & $\begin{array}{l}\text { - un mercado para la venta de su } \\
\text { prodcuto } \\
\text { - } \\
\text { - } \\
\text { - el único que le compra a granel }\end{array}$ \\
\hline CLUSA & $\begin{array}{l}\text { - } \text { semilla en consignación } \\
\text { un producto natural integral, que } \\
\text { puede explotar como atributo del } \\
\text { producto en la comercialización de } \\
\text { un segmento de mercado }\end{array}$ & $\begin{array}{l}\text { - es el único cliente que llegaba } \\
\text { hasta Tecuaname a traer el } \\
\text { producto } \\
\text { - en elámbito nacional es el cliente } \\
\text { que les compra a mejor precio } \\
\text { la semilla }\end{array}$ \\
\hline ESPANICA & $\begin{array}{ll}\text { - } & \text { reconocimiento } \\
\text { - } & \text { prestigio } \\
\text { - } & \text { legitimidad en su iniciativa. } \\
\text { - } & \text { producto de buena calidad }\end{array}$ & $\begin{array}{l}\text { - intermediario exclusivo a nivel } \\
\text { internacional } \\
\text { - mayor margen de ganancias } \\
\text { - garantiza buen precio del } \\
\text { producto } \\
\text { - } \text { relación estable de mercado } \\
\text { - relación de cooperación } \\
\text { - } \text { relación de solidaridad }\end{array}$ \\
\hline
\end{tabular}

Fuente: elaboración propia sobre la base de entrevistas realizadas a las mujeres de la cooperativa, al CIPRÉS, a Tienda Naturaleza ya CLUSA.

Las redes sociales son parte de mecanismos de colaboración entre unos y otros agentes. Muchas de ellas son construidas con lazos fuertes y otras con lazos más débiles. Además, su formación responde a la vitalidad y capacidad de los actores para relacionarse, socializar y solidarizarse en la búsqueda del mejoramiento económico.

Entre las mujeres, a lo interno de la cooperativa, se han construido lazos muy fuertes, relaciones afectivas de amistad, apoyo, cooperación e identidad que las mantienen muy unidas. Estas relaciones estrechas son la razón principal por la que la cooperativa se ha mantenido unida, pese a los prolongados períodos de inactividad en el procesamiento de la semilla.

La relación COAGRUM-CIPRES se ha construido con lazos muy fuertes, forjándose en base a relaciones afectivas y, en cierta manera, paternalistas de parte del CIPRES. Las mujeres creen que necesitan al CIPRES para sobre vivir, aunque han logrado construir todo el negocio para salir a flote por ellas mismas. 
Respecto a la comercialización, las relaciones con sus clientes son pocas y ocasionales: venden semilla en promedio dos o tres veces al año, forjándose relaciones menos estables, más débiles, sobre todo porque la compra venta del producto se realiza ocasionalmente. Aunque la actividad se desarrolla desde hace seis años, la cooperativa sólo cuenta con cuatro clientes y la única relación que permanente y constantes es la que se tiene con Industrias Páramo, que se caracteriza por la tolerancia al incumplimiento. Por ejemplo, retrasos de hasta ocho meses en los pagos. En otras palabras, las mujeres de la cooperativa no han logrado expandir su mercado por la debilidad de las relaciones que tienen con sus clientes, y porque no buscan otros nuevos.

El enfoque de redes en la comercialización demuestra ser una herramienta útil para entender la dinámica del comercio, más allá del precio/ganancia, donde las mujeres siguen unidas, aunque no ganan mucho dinero ni tienen un trabajo sistemático y periódico durante el año, porque encuentran en sí mismas y en la relación con la organización que les apoya mecanismos que les permiten sobreponerse a las dificultades económicas y continuar luchando por comercializar.

\section{Discusión de los resultados de la investigación}

La comercialización es una actividad difícil para mujeres que se encuentran en condiciones de pobreza, en una comunidad donde no hay empleo, con limitaciones de transporte que, además, es caro para viajar fuera de la comunidad.

Las cooperadas han encontrado en el CIPRES su única esperanza de sobrevivencia, pues las políticas públicas no se ocupan de los sectores empobrecidos y, menos aun, de las mujeres.

\section{1. ¿Qué supone ser asociativo y autogestionario?}

La experiencia de comercialización de las mujeres de Tecuaname ha sido conceptualizada respecto a un modelo de economía popular con tendencia asociativa y autogestionaria, interesado en mostrar sus posibilidades para escalar al crecimiento y constituirse en una alternativa para el desarrollo en el conjunto de la economía nacional.

En Nicaragua, la política económica ha concentrado sus expectativas de reactivación en la economía formal (empresarial), partiendo de que desde esta lógica se logra el crecimiento y, por ende, el bienestar social de la población, descuidando la economía mercantil simple del campo y la ciudad, donde se encuentran las mujeres de Tecuaname.

Hay dos conceptos claves para el desarrollo de este modelo: la autogestión y la asociatividad. Se entiende por asociatividad la unificación de esfuerzos para beneficio común de todas; y por autogestión, la gestión democrática o colectiva de los recursos en función de sus intereses y necesidades.

En condiciones de pobreza y escasez de recursos, asociarse en busca de una alternativa para sobrevivir es una estrategia viable pero, en la práctica, los planteamientos de asociatividad y autogestión suponen capacidades de gestión y decisión de parte de los 
actores involucrados, que las mujeres de Tecuaname todavía no han desarrollado, por diversas razones.

Dentro de la experiencia de comercialización, se observa que es difícil para una organización evitar generar efectos negativos en su intervención. Por ello, a pesar del esfuerzo que el CIPRES ha realizado dando a estas mujeres otra expectativa para sus vidas, se producen efectos contrarios al modelo teóricamente planteado. El proceso de intervención ha limitado la generación de mayores capacidades en las mujeres, de cara a las que la experiencia requiere, porque se ha creado una relación de dependencia hacia el organismo que las apoya.

El CIPRES ha introducido a estas mujeres a la producción, acopio, procesamiento, y comercialización del marañón; las ha apoyado en otras actividades como huertos familiares, capacitaciones para procesar mermeladas de frutas, y otros. Pero no todo se puede prever cuando se esta incidiendo. Casi siempre se generan efectos colaterales que pueden ser negativos.

A la vez, existe una tensión en el discurso cuando se habla de asociatividad y autogestión, porque implica fomentar capacidades y potencialidades autogestionarias de los sujetos pero, en la práctica, el organismo que las apoya ha centrado sus esfuerzos en los recursos materiales, descuidando el desarrollo de las capacidades autogestionarias, requeridas en el proceso de comercialización.

Como diría Giddens, en la sociedad existe la estructura que es producente, y la que es producto, entendiendo estructura por regla (norma) y regularidad. En este caso, el organismo ha producido su razonamiento en las cooperadas, las estructuras producen acciones, hace posible las acciones, las acciones sin estructuras no son posibles.

Las estructuras son hechas por hombres y mujeres y, a través de las acciones, se reproducen. En nuestro caso de estudio, las socias de la cooperativa creen que necesitan el apoyo financiero del organismo para avanzar. Esta idea ha moldeado su organización. Sin embargo, el modelo autogestionario de desarrollo apunta a expandir sus capacidades humanas con recursos propios.

El que las mujeres no hayan logrado desarrollar mayores capacidades de autogestión ha implicado que, algunas de las fases de la cadena, no muestren la solidez que esta experiencia necesita y, por ende, no se ha logrado comercializar el marañón a mayor escala.

\subsection{El dilema de ser productoras, procesadoras y comerciantes}

Las mujeres de Tecuaname se han desarrollado en su propio campo. Algunas son amas de casa; otras, mujeres que han emigrado a la ciudad en busca de empleo domestico. Al mismo tiempo, han crecido con una relación directa con la agricultura, porque sus cónyuges realizan una economía de autoconsumo.

Las mujeres han desarrollado patrones de percepción, pensamiento y acción que han constituido su propio habitus. Este campo de las mujeres ha sido construido en base a la red 
de relaciones entre las posiciones objetivas que hay en él. Estas relaciones existen separadas de la conciencia y la voluntad colectiva.

En el proceso, las mujeres han asumido varios roles a la vez: amas de casa, productoras, procesadoras y comerciantes, roles que las mujeres no han logrado asumir en su totalidad, ya que todavía no tienen el control de la producción y la comercialización. Actualmente son los eslabones más débiles de la cadena. El mejor rol que las mujeres han asumido es el de procesadoras del marañón o, dicho en otros términos, productoras de la nuez de marañón.

Respecto de la producción, la decisión de asumirla directamente se volvió un problema. Las 10 manzanas de tierra, más que una oportunidad, son una amenaza porque se encuentran a tres kilómetros de la comunidad e implican riesgo porque, cada día, dos cooperadas tienen que caminar o cabalgar para cuidar el cultivo. Además, en los seis años que tienen de manejar la plantación, todavía no han visto fruto²

Las mujeres de COAGRUM no han logrado asumir por completo el rol de ser productoras, procesadoras y comerciantes a la vez, roles que plantea el CIPRES desde su modelo. Este cambio es un proceso complejo y a largo plazo, que no depende solo de los recursos, sino también del crecimiento y de la formación personal de las mujeres, que se ha dado, pero muy lentamente y no a la velocidad que esta experiencia requiere para ser exitosa.

Esto no significa que esta experiencia no haya cambiado a las mujeres. Ha habido grandes cambios en ellas, sobre todo en lo que se r efiere a su autoestima: tras seis años de estar organizadas y recibir el apoyo del CIPRES, se sienten valoradas ante su pareja, ante la comunidad y ante el CIPRES; desde que están organizadas, tienen un espacio propio, tienen identidad de grupo, han logrado irrumpir los patrones de machismo presentes en sus parejas y en la comunidad de Tecuaname.

Desde la perspectiva de los actores sociales, según Giddens, los cambios no se pueden predecir, ni predeterminar, ya que los procesos no dependen sólo de las intervenciones externas, sino también de los sujetos.

\subsection{Lazos fuertes y débiles en la cadena de comercialización del marañón}

El enfoque de cadenas utilizado en este estudio para el análisis del comercio, permite ver que las mujeres, aunque se encuentran ubicadas a 81 kilómetros de la capital, no desarrollan una actividad aislada, de manera independiente. Al hacer la descripción de la cadena de comercialización del marañón, es útil darnos cuenta que están vinculadas a una serie de actores que participan en las distintas fases de la cadena.

En esta experiencia, las mujeres de COAGRUM como cooperativa se encuentran satisfechas y fortalecidas porque han construido, a lo interno, relaciones sociales con lazos fuertes. Entre ellas hay relaciones afectivas, de amistad, apoyo y cooperación que las mantienen muy unidas. Estas relaciones se han construido en base a la constancia con que se reúnen, cada 15 o 30 días; la cercanía entre ellas, ya que varias son vecinas. Estas relaciones tan estrechas han dado lugar a que la cooperativa se mantenga a pesar del inconstante trabajo que han obtenido con el marañón. 
Los lazos de la cooperativa con el CIPRES son fuertes. Es la relación más duradera, su principal acompañante y aliado en todo este proceso, que ha gestionado los recursos y les ha contactado con casi todos sus clientes. Con Industrias Páramo, es la relación en que se ha dado la mayor cantidad de arreglos, la más estable a pesar de ser la más conflictiva, el cliente con mayor antigüedad y que les compra más producto de manera constante.

Existe una relación ocasional con Tienda Naturaleza, CLUSA y ESPANICA que han forjado una relación con lazos débiles con el mercado del marañón. Lazos de este tipo, aunque se consideren débiles, son sumamente útiles ya que permiten a las mujeres vincularse con otros miembros de la sociedad y dar a conocer el producto. Además, de esta forma, van tejiendo lazos que les permiten aumentar sus capacidades de colocar su producto en el mercado, aunque sea en pequeñas cantidades.

Pero, aunque las mujeres no han logrado procesar y comercializar el marañón en grandes cantidades, no es una razón que impida que la actividad misma sea rentable, como se puede apreciar en el siguiente cuadro.

Cuadro 6. Rentabilidad de 20 qq de marañón

\begin{tabular}{|l|c|}
\hline Productos/Insumos & Costos e ingresos en C\$ \\
\hline 20 qq de marañón & 3000 \\
\hline Mano de obra & 1890 \\
\hline Leña & 100 \\
\hline Fósforos & 1 \\
\hline Gas & 3 \\
\hline Transporte de 3 qq & 30 \\
\hline Pasaje & 50 \\
\hline Viáticos Alimentos & 70 \\
\hline Total costos & $\mathrm{C} \$ 5,144$ \\
\hline & $\mathrm{C} \$ 11.520$ \\
\hline 20 qq de marañòn $(20 \times 12)=240 \mathrm{lb} \quad \mathrm{s}=1,280$ paquetes \\
\hline Total ganancia $(11.520-5,144)$ & $\mathrm{C} \$ 6,376$ \\
\hline
\end{tabular}

Fuente: elaboración propia en base a entrevistas realizadas a mujeres de Tecuaname.

*1 quintal de semilla de marañòn equivale a 12 libras promedio de nuez procesada.

*20 quintales de marañón se procesan en una semana.

Estos datos demuestran que la actividad de comercializaciòn es rentable y que, por tanto, vale la pena pensar en expandir el procesamiento y la comercialización. 


\section{Conclusiones}

El modelo ha evolucionado en la práctica con las mujeres de COAGRUM en la comunidad de Tecuaname, ya que las ha dirigido mediante su aliado clave en un recorrido por las fases de producción, acopio, procesamiento y comercialización del marañón, proceso que ha implicado mucho esfuerzo para ellas, aunque las mujeres van lentamente asumiendo los diferentes roles que implica todo este proceso.

El que las mujeres hayan puesto en práctica este modelo, más que una experiencia interesante y funcional para sus vidas, ha significado una alternativa de vida que les ha proporcionado los medios para crear una fuente de trabajo con perspectivas buenas, tanto para ellas como para la comunidad, y un espacio de identidad propia como grupo que les permite desarrollar acciones conjuntas.

En lo que respecta al enfoque asociativo que plantea el modelo, las mujeres han logrado grandes avances: la organización cooperativa es bastante sólida, con un alto potencial de aprendizaje en esta área y con muchas expectativas de crecimiento. Además, se ha logrado desarrollar el capital humano de las mujeres.

Por otro lado, en el aspecto autogestionario del modelo, se han dado varias limitaciones, sobre todo por el grado de dependencia que se ha creado en la relación con el CIPRES, donde las mujeres no desarrollan su protagonismo en la actividad comercial.

De todo esto, se puede concluir que las mujeres necesitan asumir con mayor eficiencia la parte productiva y la comercialización necesita ser desarrollada por otra instancia desde afuera de la cooperativa, pero vinculada a ella. Dos opciones parecen viables: la primera, que la unidad de comercialización del CIPRES lo asuma como parte de su responsabilidad y sea quien, al estar más cerca del mercado, influya también en la capacidad productiva de la cooperativa; o bien, que la cooperativa misma pueda crear una unidad de comercialización especializada que se encargue de trabajar el mercado exclusivamente.

Esta experiencia de comercialización ha sido fuertemente influenciada y dirigida por un modelo que se contrapone a la lógica del pensamiento dominante, la del libre mercado, que basa sus expectativas en las capacidades individuales de los más fuertes.

Aunque el CIPRES tiene una lógica diferente y las ha apoyado mucho en todo lo relacionado con el mercado su incidencia es débil. La comercialización es la fase de la cadena en que las mujeres menos han asumido ese rol, porque están distantes de su principal mercado y, para ellas, dejar la casa para salir a comercializar a la ciudad, no es una decisión fácil de tomar.

El CIPRES había tomado el papel protagónico en esta fase; les había asegurado la venta de su producto, conectándolas con casi todos sus clientes, aunque en menor medida en los últimos años. Por otro lado, la construcción social de ser mujer de una comunidad rural es uno de los obstáculos más grandes para que ellas comercialicen directamente.

Mucho del potencial de las mujeres se ha invertido en otras actividades que no están relacionadas directamente con el marañón, en la búsqueda de subsistencia. Algunas de 
ellas han desarrollado habilidades para ser comerciantes por cuenta propia. Así. dos de las mujeres actualmente comercializan cuajada y cajeta, encontrando a sus principales clientes en las oficinas del CIPRES y, otra de ellas, se ha dedicado también a comercializar tortillas de maíz y cajeta en su comunidad.

Para ellas, lo que les va arreglar el negocio es que la plantación les dé fruto pero, realmente lo que necesitan, es asegurar la materia prima. Hay lugares como Laguna de Perlas donde hay semilla de marañón y pueden acopiar el producto.

Finalmente, la experiencia del marañón revela:

- Para los grupos de mujeres, el solo hecho de persistir y hacerlo juntas, aunque con dificultades y pequeños avances, les genera un sentido de autoestima: se ven, rien juntas, comparten historias, sudan juntas y comparten momentos que les generan alegría.

- Los vínculos entre las mujeres organizadas, CIPRES, mercado tradicional y mercado alternativo, tiene sus sinergias que auguran buenas perspectivas, aunque la diversificación en actividades y objetivos de las mujeres (plantíos, casas, marañón, etc.), no les permite escalar a la comercialización con el marañón y apostar a construir sus ventajas competitivas en el mediano plazo. Una limitante al propósito último es la ausencia de estudios sobre el comercio.

- $\quad$ Este presente trabajo, por el tema y la perspectiva utilizada, es exploratorio. Esperamos pueda contribuir a que las mujeres de COAGRUM y la dirección de CIPRES puedan reflexionar, revisar sus propios esquemas y ver el producto marañón como un rubro competitivo; ver a las mujeres como sujetos en permanente aprendizaje y crecimiento y requiriendo de otros tipos de acompañamiento; ver el comercio como lo que es: competitividad y cooperación, donde ambos están involucrados pero necesitan redefinir el rol de cada uno.

\section{Recomendaciones}

Las recomendaciones propuestas en el estudio giran en torno a favorecer a las mujeres de la cooperativa de COAGRUM.

- Necesitan obtener más información acerca de la producción del marañón a nivel nacional, para iniciar la búsqueda del producto por ellas mismas, para asegurar el acopio, y no depender de la producción local.

- Gestionar crédito para acopiar más producto fuera de la comunidad. Aunque el precio de la semilla sea más caro, el procesamiento les va a permitir obtener mayores ganancias.

- Unificar esfuerzos para desarrollar estrategias de comercialización que les faciliten su inclusión en otros mercados, tanto a nivel nacional como internacional. Movilizarse a ofertar el producto. 
- Capacitar a las mujeres de la cooperativa que tienen mayores habilidades para comercializar y liberarlas de otras responsabilidades para que puedan asumir con éxito esta tarea.

- Las mujeres necesitan encontrar una forma de resolver los asuntos domésticos de sus hogares que les demandan tiempo y les limitan aportar en la cooperativa.

- Aprovechar la relación con lazos tan fuertes que tienen con el CIPRES para desarrollar estrategias de acopio y comercialización de marañón.

- Invertir en publicidad, nuevo empaque atractivo y bolsas de diferentes tamaños con el codigo de barras

- Fortalecer los lazos con otras cooperativas, con el fin de mejorar las capacidades asociativas y autogestionarias

32 - Facilitar el proceso de empoderamiento y desarrollo personal de las mujeres, para potenciar sus capacidades y capital humano a través de grupos de autoayuda

\section{Notas}

2 Primero, por la falta de fertilidad de la tierra y luego, el Huracán Mitch les dañó la plantación.

\section{Referencias bibliográficas}

-GINER S.; LAMO de ESPINOZA, E. y TORRES, C. (1998). Diccionario de Sociología, Managua, UNAN

-GIDDENS, A (1989). La constitución de la sociedad. Sao Pablo. Editorial Martíns.

-MARTINEZ, M.C. (2001). Situación actual y perspectivas a nivel de planificación sobe el desarrollo productivo, agroindustrial y comercialización de la nuez de marañón en Nicaragua. Managua. CIPRES.

-LOZARES, C. (1999). Curso de especialización de poslicenciatura en centroamérica .. Posgrado en formación de formadores/as sociales. Managua, UCA.

-PARILLI, M.D. (2002). "Análisis subsectorial en la rama cuero-calzado de Nicaragua". Cuaderno de Investigación No. 14. Managua. Nitlapán, UCA. 